\title{
Improved Sensitivity of Multi-adduct Derivatives of Fullerene
}

\author{
Tetsuya Tada, Koichiro Uekusa, and Toshihiko Kanayama \\ Joint Research Center for Atom Technology (JRCAT), \\ National Institute of Advanced Industrial Science and Technology (AIST), \\ 1-1-4 Higashi, Tsukuba-shi, Ibaraki 305-8562, Japan \\ Takahiro Nakayama \\ Joint Research Center for Atom Technology (JRCAT), \\ Angstrom Technology Partnership (ATP) \\ 1-1-4 Higashi, Tsukuba-shi, Ibaraki 305-0046, Japan
}

\author{
Ross Chapman, Wai Yee Cheung, Louise Eden, Irfan Hussain, Mark Jennings, Jacob Perkins, \\ Marcus Phillips, Jon A. Preece, and Elwyn Shelley \\ School of Chemistry, The University of Birmingham Edgbaston, Birmingham B15 2TT, United Kingdom
}

\begin{abstract}
Methanofullerenes, a class of $\mathrm{C}_{60}$ derivatives, act as negative type e-beam resists with 10-nm resolution and high dry-etch durability. Their sensitivity is $\sim 10^{-3} \mathrm{C} / \mathrm{cm}^{2}$, one order of magnitude better than that of $\mathrm{C}_{60}$. We studied sensitivities of methanofullerene resists by systematically changing side chains and have found that the methano bridge and $>\mathrm{C}=\mathrm{O}$ in the side chains are important in the sensitivity improvement. We realized further sensitivity improvement by synthesizing methanofullerene with 4-6 side chains. This has about two orders of magnitude higher sensitivity $\left(3.8 \times 10^{-4} \mathrm{C} / \mathrm{cm}^{2}\right)$ than that of $\mathrm{C}_{60}$.

Keywords: fullerene, methanofullerene, $\mathrm{C}_{60}$, electron beam resist, nanolithography
\end{abstract}

\section{Introduction}

We discovered that electron beam (e-beam) irradiation reduces the dissolution rate of $\mathrm{C}_{60}$ films in organic solvents such as monochlorobenzene (MCB), and that it can be used as a high resolution negative e-beam resist with high dry-etch durability $[1,2]$. However $\mathrm{C}_{60}$ has some drawbacks for use as an e-beam resist. First, $\mathrm{C}_{60}$ films cannot be prepared by spin-coating because of the low viscosity of the $\mathrm{C}_{60}$ solutions. Second, the sensitivity of $\mathrm{C}_{60}$ resist is $\sim 0.01 \mathrm{C} / \mathrm{cm}^{2}$, which is $2-3$ orders of magnitude lower than that of poly(methylmethacrylate) (PMMA) although it is better than that of inorganic resists $[3,4]$.

To solve these problems, we adopted $\mathrm{C}_{60}$ derivatives, methanofullerene, as e-beam resists
$[5,6]$. Addition of side chains to a $\mathrm{C}_{60}$ cage enhanced the solubility in organic solvents and the viscosity of its solution, which enabled spin-coating to prepare the uniform films.

The methanofullerenes actually acted as a negative type e-beam resist with high resolution and high dry-etch durability. Their sensitivities were $\sim 10^{-3} \mathrm{C} / \mathrm{cm}^{2}$, about one order of magnitude higher than that of $\mathrm{C}_{60}$. They are, however, still one order of magnitude lower than that of PMMA.

In this paper, we investigate factors influencing the sensitivity to develop new methanofullerene resists with higher sensitivity.

2. Sensitivity improvement of methanofullerene resists 


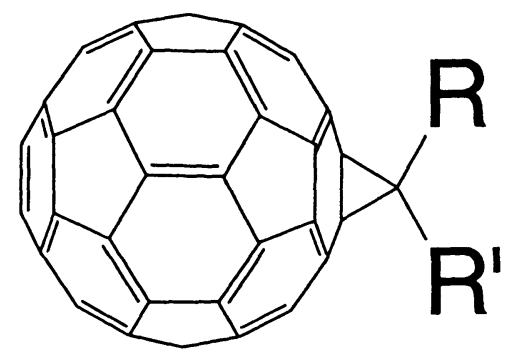

Fig.1 Ageneralized schematic of a methanofullerene $\mathrm{C}_{60}$ derivative with one addend.

Figure 1 shows a generalized schematic of the methanofullerene with one addend. A carbon atom is added to the fullerene cage to form a methano bridge (three membered carbon ring).

We investigated three kinds of methanofullerenes with different atoms at the end of side chains, $\mathrm{S}, \mathrm{Cl}$, and I, which are labeled as MTF-Ts, MTF-Cl, and MTF-I, respectively (Fig.2). A scattering cross section of an atom against e-beam depends on the atomic weight: a heavier atom generally has a larger cross section. Thus, it is expected that MTF-I has a highest sensitivity because $I$ is the heaviest among the three.

To measure the response of the methanofullerene films to e-beam irradiation, about 300 -nm thick films of MTF-Ts, MTF-Cl, and MTF-I were exposed to 20 keV e-beam using a Hitachi S4500 scanning electron microscope (SEM). Then the samples were immersed in MCB for $1 \mathrm{~min}$ and rinsed in isopropyl alcohol (IPA) for $10 \mathrm{~s}$ and the remaining film thickness was measured by a surface profiler (Dektak3 ST, Sloan).

Figure 3 shows responses of the

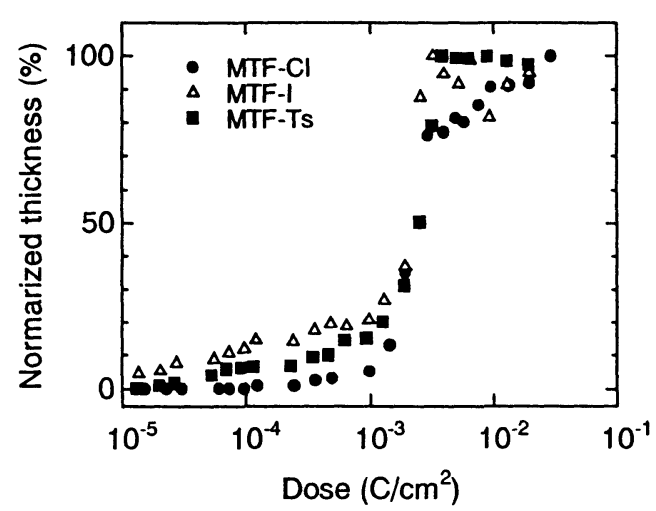

Fig.3 Thicknesses of the methanofullerene films (MTF-Cl, MTF-I, MTF-Ts) after the development as a function of e-beam dose.

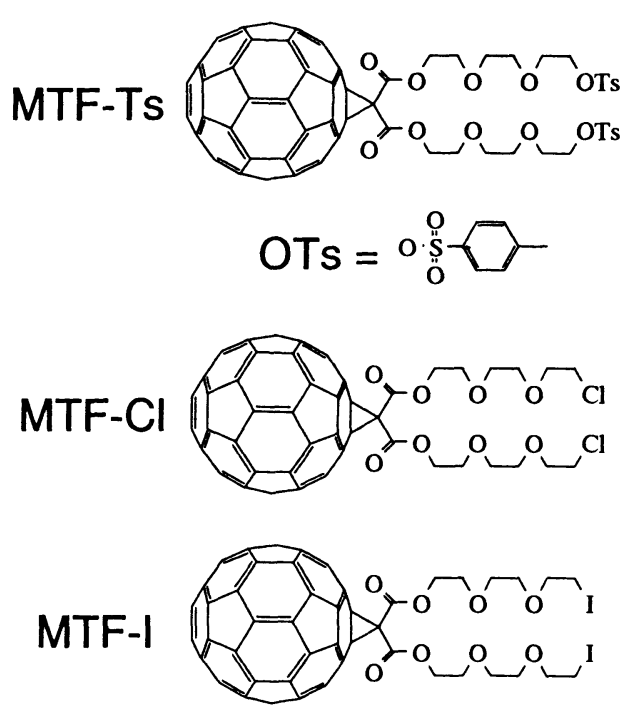

Fig.2 Methanofullerenes with different atoms at the end of side chains, $\mathrm{S}, \mathrm{Cl}$, and $\mathrm{I}$, which are labeled as MTF-Ts, MTF-Cl, and MTF-I.

methanofullerene films to e-beam, where the film thicknesses after developed in MCB for $1 \mathrm{~min}$ are plotted as a function of the electron dose. Although the unexposed area of the film was throughly solved in MCB within $10 \mathrm{~s}$, the methanofullerene films became insoluble with the dose higher than $\sim 2 \times$ $10^{-3} \mathrm{C} / \mathrm{cm}^{2}$. The sensitivities of the methanofullerenes, defined as the mean value of the two turning points on the graph, are $2.0 \times 10^{-3} \mathrm{C} / \mathrm{cm}^{2}$ for MTF-Ts, $2.5 \times 10^{-3} \mathrm{C} / \mathrm{cm}^{2}$ for MTF-Cl and $2.3 \times 10^{-3} \mathrm{C} / \mathrm{cm}^{2}$ for MTF-I. These are one order of magnitude better than that of $\mathrm{C}_{60}$ resist $\left(0.02 \mathrm{C} / \mathrm{cm}^{2}\right)$. Among the three methanofullerene films, the sensitivity difference is very small. This means that the atoms at chain-ends have only a weak effect on the sensitivity.

In our previous letters [7,8], we investigated resist sensitivities of methanofullerenes by systematically changing the length of side chain, and showed that the sensitivity was also only weakly dependent on the chain length. These results suggests that the sensitivity enhancement in methanofullerenes are caused mainly by the structures near the connection sites between the $\mathrm{C}_{60}$ cage and the side chain.

There are two characteristic structures in all the methanofullerenes utilized in our experiments: methano bridge and $>\mathrm{C}=\mathrm{O}$ near the connection sites. To assess the effects of these structures we measured sensitivities of a Diels-Alder derivative of $\mathrm{C}_{60}$ (DA) and a methanofullerene (MTF11) shown in the Fig.4. MTF11 does not have $>\mathrm{C}=\mathrm{O}$ in the side chain, and 


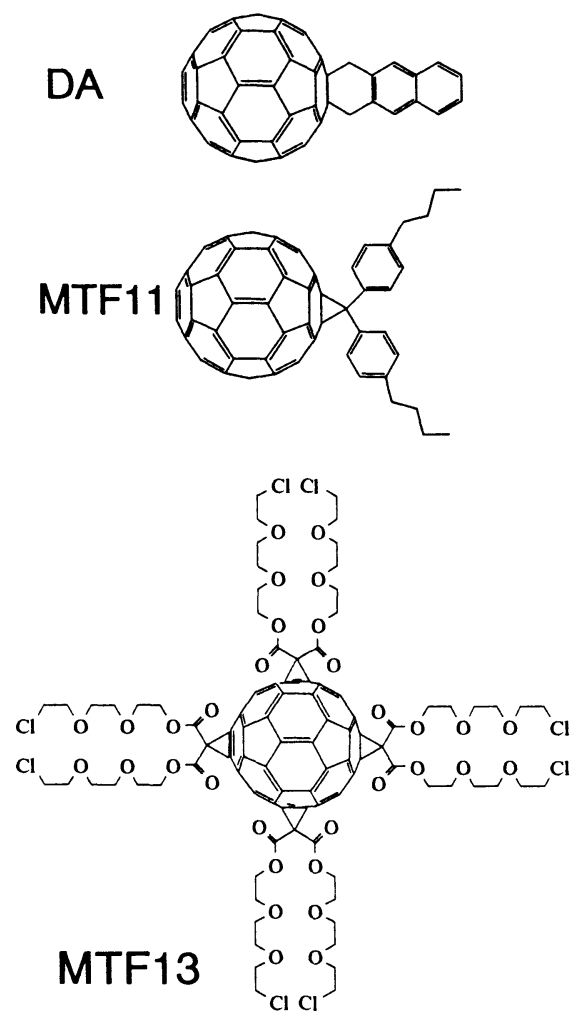

Fig.4 Chemical structures of DA, MTF11, and MTF13.

DA does not have either a methano bridge nor an oxygen atom.

The DA and MTF-11 films were exposed to 20 $\mathrm{kV}$ e-beams and developed in MCB for one minute. The remaining thicknesses of DA and MTF11 are plotted in Fig.5. Those of $\mathrm{C}_{60}$ and MTF-Ts are also plotted for comparison. The sensitivity of DA is $0.01 \mathrm{C} / \mathrm{cm}^{2}$, which is almost the same as that of $\mathrm{C}_{60}$. This indicates the presence of the methano bridge plays an important role in the sensitivity

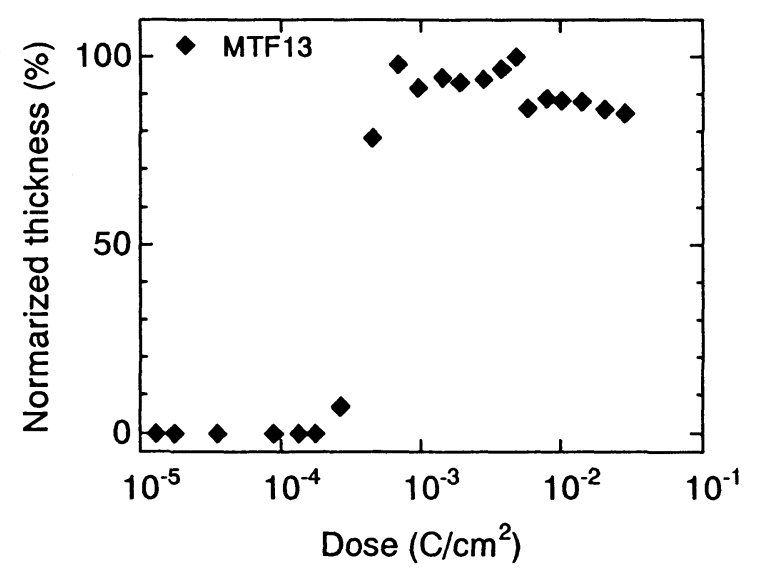

Fig.6 Thickness of MTF 13 film after development as a function of e-beam dose.

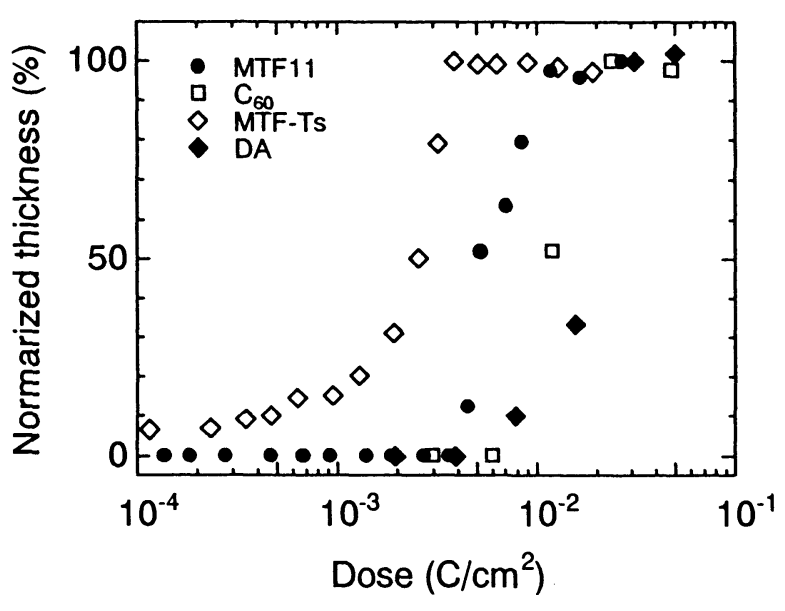

Fig.5 Thicknesses of $\mathrm{C}_{60}$ and $\mathrm{C}_{60}$ derivatives (MTF11, MTF-Ts, and DA) after development as a function of e-beam dose.

improvement.

The sensitivity of MTF11 is about $6.4 \times 10^{-}$ ${ }^{3} \mathrm{C} / \mathrm{cm}^{2}$, which is between $\mathrm{C}_{60}$ and the methanofullerenes with $>\mathrm{C}=\mathrm{O}$. The fact that the MTF without $>\mathrm{C}=\mathrm{O}$ has the lower sensitivity indicates that the oxygen atoms near the cage also contribute to the sensitivity improvement. Oxygen has high electronegativity, which may cause inhomogeneous charge distribution in the $\mathrm{C}_{60}$ cage. Thus, the addition of oxygen atom near the cage may make $\mathrm{C}_{60}$ more vulnerable to e-beam.

From the above results, we can obtain a guideline to design a higher sensitivity resist: methanofullerene having more side chains with $>\mathrm{C}=\mathrm{O}$ near the connection sites. Thus, we synthesized a multi-adduct methanofullerene, MTF13. We used a mixture of tetra, penta, and hexa

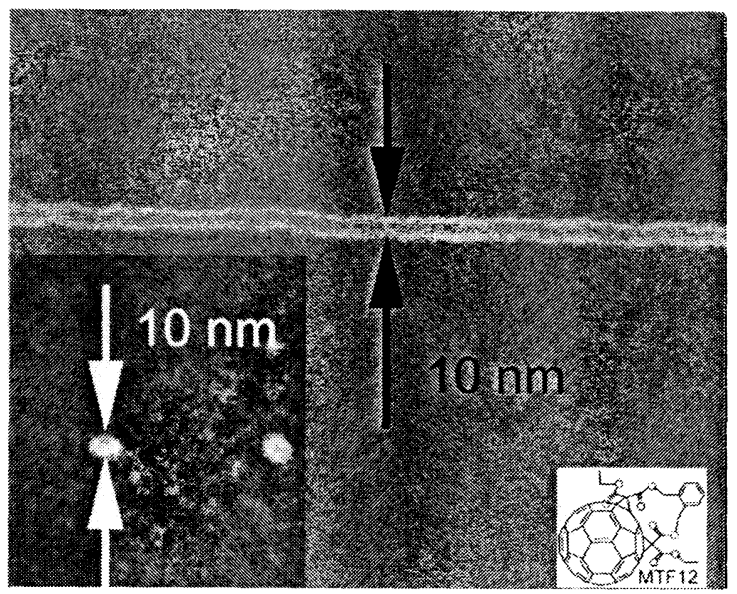

Fig.7 SEM pictures of the defined dots and lines. The dot patterns with $10 \mathrm{~nm}$ diameter and lines. 


\begin{tabular}{|c|c|c|c|c|}
\hline Resist & Type & Resolution & Dry-etch durability & Senstivity $\left(\mathrm{C} / \mathrm{cm}^{2}\right)$ \\
\hline $\begin{array}{l}\text { MTF-Cl } \\
\text { MTF13 }\end{array}$ & $\begin{array}{l}\text { negative } \\
\text { negative }\end{array}$ & $\begin{array}{c}10 \mathrm{~nm} \\
10 \mathrm{~nm}\end{array}$ & $\begin{array}{l}4.1 \\
2.9\end{array}$ & $\begin{array}{l}2.5 \mathrm{E}-03 \\
3.8 \mathrm{E}-04\end{array}$ \\
\hline $\mathrm{C}_{60}$ & negative & $10 \mathrm{~nm}$ & 6.4 & $1.5 \mathrm{E}-02$ \\
\hline SAL 601 & negative & $50 \mathrm{~nm}$ & 2.8 & $2.1 \mathrm{E}-06$ \\
\hline Polystyrene & negative & $10 \mathrm{~nm}^{\mathrm{a})}$ & $3.5^{b)}$ & $5.0 \mathrm{E}-03^{\text {a) }}$ \\
\hline PMMA ${ }^{c)}$ & positive & $10 \mathrm{~nm}$ & 1.6 & $5.0 \mathrm{E}-05$ \\
\hline
\end{tabular}

Table I Properties of various e-beam nano resists.

adduct methanofullerenes (Fig.4). Only the tetra adduct derivative is shown in the figure.

Figure 6 shows an e-beam response curve of MTF13. Drastic improvement of the sensitivity is observed. The sensitivity of MTF13 is estimated to be $3.8 \times 10^{-4} \mathrm{C} / \mathrm{cm}^{2}$. This is about one order of magnitude better than that of mono adduct methanofullerenes.

\section{Performance of the methanofullerene resists}

To demonstrate performance of the methanofullerene resists, nanometer scale patterns were defined in MTF12 (Fig.7) using the SEM equipped with a pattern generator (Crestec, CPG1000). Figure 7 shows SEM pictures of the defined dots and lines. The diameter of the dots was $10 \mathrm{~nm}$ and the line width was $10 \mathrm{~nm}$. In this experiment, the minimum pattern size is not limited by the resist resolution, but by the performance of the exposure system.

Next we compare resist properties ( resolution, sensitivity, and dry-etch durability) of the methanofullerenes (MTF-Cl and MTF13) with other e-beam resists: PMMA, polystyrene, a novolac based e-beam resist (SAL 601, Shipley), and $\mathrm{C}_{60}$.

Dry-etch durability was estimated by the etch rate ratio of Si to the resists using reactive ion etching (L-201D-L, ANELVA). The etching conditions were as follows. The etching gas was mixture of $\mathrm{SF}_{6}$ and $\mathrm{CF}_{4}$ with flow rate of $12.5 \mathrm{sccm}$ for each and the total pressure was $0.5 \mathrm{~Pa}$. The incident rf power was $18 \mathrm{~W}$. Before the etching, the resist films were exposed to e-beam.

The properties of the resists are summarized in Table I. PMMA, has higher sensitivity and $10-\mathrm{nm}$ scale resolution, but the dry-etch durability is weak. SAL601 has good dry-etch durability and high sensitivity, but the resolution is not so high. Compared with other resists, the methanofullerene resists are good e-beam resists capable of high resolution, high dry-etch durability and good sensitivity.

\section{Summary}

The methanofullerene resists act as negative type e-beam resists with high resolution and high dry-etch durability. Their higher sensitivity than that of $\mathrm{C}_{60}$ results from the presence of the methano bridge and $>\mathrm{C}=\mathrm{O}$. We realized further two orders of higher sensitivity than that of $\mathrm{C}_{60}$ by synthesizing methanofullerene with 4-6 addends.

\section{Acknowledgments}

This work is partly supported by NEDO. The authors would like to thank Prof. J. Nishimura and Dr. Y. Nakamura at Gunma University for the synthesis of the Diels-Alder adduct of $\mathrm{C}_{60}$.

\section{References}

1 T. Tada and T. Kanayama, Jpn. J. Appl. Phys. 35 (1996) L63.

2. T. Tada and T. Kanayama, J. Photopolymer Sci. Technol. 10 (1997) 647.

3. T. Tada and T. Kanayama, J. Vac. Sci. Technol. B 11(1993) 2229.

4. P.E. Allen, D.P. Griffis, Z.J. Radzimski, and P.E. Russell, J. Vac. Sci. Technol. A 10 (1992) 965

5. A.P.G. Robinson, R.E. Palmer, T. Tada, T. Kanayama, J.A. Preece, Appl. Phys. Lett. 72 (1998) 1302.

6. T. Tada, T. Kanayama, A.P.G. Robinson, R.E. Palmer, J.A. Preece, J. Photopolymer Sci. Technol. 11 (1998) 581.

7. A.P.G. Robinson, M.R.C. Hunt, R.E. Palmer, T. Tada, T. Kanayama, J.A. Preece, D. Philp, U. Jonas, and F. Deiderich, Chem Phys. Lett., 289, (1998) 586.

8. A.P.G. Robinson, R.E. Palmer, T. Tada, T. Kanayama, E.J. Shelley, D. Philp, J.A. Preece, Chem Phys. Lett., 312, (1999) 469. 